\title{
Regulation of Human Peripheral Blood Monocyte DR Antigen Expression In Vitro by Lymphokines and Recombinant Interferons
}

\author{
Marcelo B. Sztein and Patricia S. Steeg \\ Laboratory of Microbiology and Immunology, National Institute \\ of Dental Research, National Institutes of Health, \\ Bethesda, Maryland 20205 \\ Howard M. Johnson \\ Department of Microbiology, The University of Texas \\ Medical Branch, Galveston, Texas 77550 \\ Joost J. Oppenheim \\ Laboratory of Molecular Immunoregulation, National Cancer \\ Institute, Frederick Cancer Research Facility, \\ Frederick, Maryland 21701
}

bstract. The in vitro regulation of adult human monocyte DR antigen expression was studied. Normally about $75 \%$ of freshly obtained human peripheral blood monocytes express DR antigens as determined by anti-DR and complement-mediated cytotoxicity assays. DR expression on monocytes in unfractionated peripheral blood mononuclear cell cultures persisted to variable degrees for up to $5 \mathrm{~d}$ of incubation. However, when the mononuclear cells were thoroughly depleted of nonadherent cells, cultured monocytes consistently exhibited progressively decreased DR expression over 2-5 d of incubation. Readdition of nonadherent cells to the adherent cell population prevented or delayed this decrease in monocyte DR antigen expression. Thus, monocyte DR expression diminished markedly during in vitro incubation; however, the presence of nonadherent cells somehow interfered with this process. In other experiments, peripheral adherent monocytes, which had been cultured for 2-3 d to reduce their DR expression, could be induced to reexpress DR antigens after $2 \mathrm{~d}$ of incubation with

Dr. Sztein's current address is The Cancer Research Laboratories, The George Washington University Medical Center, Washington, DC., 20037. Dr. Steeg's current address is Laboratory of Developmental Biology and Anomalies, National Institute of Dental Research, National Institutes of Health, Bethesda, MD 20205. Address reprint requests to Dr. Oppenheim.

Received for publication 22 March 1983 and in revised form 11 October 1983.

The Journal of Clinical Investigation, Inc.

Volume 73, February 1984, 556-565 unpurified lymphokine-containing culture supernatants, recombinant human interferon- $\alpha$, or recombinant human gamma interferon (IFN- $\gamma$ ). The reinduction of DR expression on human monocytes by lymphokines was abrogated by an antiserum produced to the synthetic $\mathrm{N}$ terminal amino acids of human IFN- $\gamma$, indicating that IFN- $\gamma$ is the active mediator in the lymphokine-containing preparations. Monocytes cultured with lymphokines or recombinant interferons also could initiate a significantly greater mixed lymphocyte response than control monocytes. Thus, IFN- $\gamma$-containing lymphokines and recombinant interferons are required to induce human monocyte DR expression and accessory cell capacity in vitro, since in their absence monocytes become DR antigen-deficient. Finally, incubation of unfractionated human mononuclear cells with anti-human IFN- $\gamma$ also promoted the loss of monocyte DR expression. These findings suggest that resting lymphocytes are probably capable of producing sufficient IFN- $\gamma$ in vitro to result in the maintenance of the monocyte DR phenotype.

\section{Introduction}

The initiation of antigen-specific, T-dependent human immune responses in vitro requires the participation of accessory cells that express DR antigens. We have investigated factors that regulate the DR antigen expression on human monocytes, a principal class of accessory cells $(1,2)$. Studies of the in vitro regulation of murine macrophage Ia antigen expression, the homologue of DR antigens $(3,4)$, have revealed that crude lymphokine-containing culture supernatant (lymphokine) induces macrophage Ia antigen expression $(5,6)$ and accessory 
cell function (6-8) in vitro. Biochemical analysis of such supernatants has indicated that the active lymphokine is similar, if not identical, to recombinant human gamma interferon (IFN$\gamma)^{1}$ (9). Furthermore, three conditions were identified which favored reversion of macrophages to the $\mathrm{Ia}^{-}$state: the absence of lymphokine preparations containing interferon (IFN) (10), corticosteroid treatment (11), and prostaglandin or prostaglandin inducers (12), all of which also inhibited the induction of macrophage Ia antigen expression even in the presence of partially purified IFN- $\gamma$.

With regard to man, Yem and Parmely (13) have reported that bacterial endotoxin and zymozan $A$ both inhibited peripheral blood monocyte DR antigen expression and accessory cell function in vitro. However, their study did not reveal any positive immunoregulatory signals. We have shown that both lymphokines and recombinant IFN- $\alpha$ (IFLrA, IFLrD) can augment the normally low DR expression of human cord blood monocytes (14). Dayton et al. (15) very recently reported that a phytohemagglutinin-stimulated peripheral blood mononuclear cell (PBMNC) culture supernatant induced enhanced levels of DR antigen expression on human histiocytic and promyelocytic cell lines. In addition, we have found that IFN can induce enhanced levels of DR antigen expression by increasing both the percentage of cells expressing DR antigens as well as the density of the DR antigens on the cell surface of the promyelocytic cell line HL60. These cell line cells normally express DR antigens, as measured by antibody and complement-mediated cell cytotoxicity, on only about $4 \%$ of the cells. ${ }^{2}$

The present study was designed to explore the immunoregulatory signals that modulate the usually high levels $(\sim 75 \%)$ of adult human peripheral blood monocyte DR antigen expression. Such studies required elucidation of negative as well as positive signals that modulate DR expression. We have observed that human peripheral blood monocytes, when cultured in the absence of contaminating nonadherent cells which presumably are releasing IFN- $\gamma$, or in the presence of anti-IFN- $\gamma$ antiserum, reduce their DR antigen expression. Conversely, both unpurified lymphokines and recombinant human IFN- $\alpha$ and IFN- $\gamma$ enhance DR antigen expression by adult monocytes in vitro.

\section{Methods}

Lymphokines. PBMNC $\left(2 \times 10^{6} / \mathrm{ml}\right)$ were incubated for $48 \mathrm{~h}$ with 2 $\mu \mathrm{g} / \mathrm{ml}$ Concanavalin A (Calbiochem-Behring Corp., San Diego, CA) in RPMI 1640 containing 2\% heat-inactivated fetal calf serum (FCS) (Lot

1. Abbreviations used in this paper: $\mathrm{CI}$, cytotoxicity index; Con $\mathrm{A}$, Concanavalin $\mathrm{A} ; \mathrm{DR}^{+}, \mathrm{DR}$ antigen expressing; $\mathrm{DR}^{-}, \mathrm{DR}$ antigen deficient; FCS, fetal calf serum; IFLrA, IFLrD, recombinant human IFN- $\alpha$; IFN, interferon; IFN- $\gamma$, recombinant human gamma IFN; IL-2, interleukin 2; lymphokine, lymphokine-containing culture supernatant; MLR, mixed lymphocyte response, PBMNC, peripheral blood mononuclear cells; SLE, systemic lupus erythematosus.

2. Steeg, P. S., M. B. Sztein, D. L. Mann, D. M. Strong, and J. J. Oppenheim. Manuscript submitted for publication.
100308, Sterile Systems, Inc., Logan, Utah), $5 \times 10^{-5}$ M 2-Mercaptoethanol (Eastman Kodak Co., Rochester, NY), $100 \mathrm{U} / \mathrm{ml}$ penicillin, and $100 \mu \mathrm{g} / \mathrm{ml}$ streptomycin (Grand Island Biological Co., Grand Island, NY). Cells were then removed by centrifugation, and culture supernatants filtered, aliquoted, and stored at $-20^{\circ} \mathrm{C}$ until usage. This supernatant exhibited $60 \mathrm{U} / \mathrm{ml}$ of antiviral activity as measured by the viral plaque inhibition assay. Control culture supernatants were prepared by culturing unstimulated PBMNC in the same medium and supplementing the culture supernatants with lectin.

Interleukin 2 (IL-2) measurement. IL-2 was assayed by its stimulating effect on proliferation of CT 6 , and IL-2-dependent cell line, as previously described (16).

IFN. Affinity-purified recombinant human leukocyte IFN- $\alpha$ (IFLrA, IFLrD) (17) were the generous gift of Dr. Sidney Pestka, HoffmannLaRoche, Inc., Nutley, NJ. IFN- $\gamma$ (18) was the generous gift of Dr. David Goeddel and Dr. Patrick Gray, Genentech, Inc. (South San Francisco, CA).

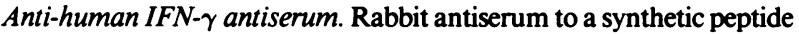
corresponding to the first $20 \mathrm{~N}$-terminal amino acids of human IFN- $\gamma$ based on cDNA sequence was prepared as described (19), and was added to the cultures in the concentrations indicated. $1 \mathrm{ml}$ of the antiserum neutralized $\sim 5,000$ units of human IFN- $\gamma$. Pretreatment of the lymphokine-containing supernatant with either the antiserum or normal rabbit serum was performed by incubating the supernatant with the antiserum or normal serum at $4^{\circ} \mathrm{C}$ for 90 min.

Peripheral blood monocyte collection and culture. PBMNC were isolated by Ficoll-Hypaque density centrifugation of blood from normal donors. 4-8 $\times 10^{5}$ PBMNC were plated per well in 96-well microtiter plates (Costar, Cambridge, Mass.) in 0.1 ml RPMI 1640 containing $1 \%$ FCS and incubated for at least $2 \mathrm{~h}$ at $37^{\circ} \mathrm{C}$. Nonadherent cells were subsequently removed by six to eight vigorous washings of the cultures. The remaining adherent PBMNC cells were 95-99\% esterase-positive, determined as described by Tucker et al. (20). To decrease the DR antigen expression of the peripheral blood monocytes, cultures were incubated for 2-3 d with either $0.1 \mathrm{ml}$ RPMI 1640 containing $10 \%$ heatinactivated FCS and antibiotics (medium), $0.1 \mathrm{ml}$ medium containing $20 \mu \mathrm{g} / \mathrm{ml}$ zymosan A (Sigma Chemical Co., St. Louis, Mo.), or antihuman IFN- $\gamma$ at the indicated dilutions. In some experiments, $1 \mu \mathrm{g} /$ $\mathrm{ml}$ polymixin B sulfate (Grand Island Biological Co.) was added to the cultures as indicated.

To induce DR antigen expression, the culture supernatants were removed and replaced with $0.2 \mathrm{ml}$ medium containing dilutions of either lymphokines or recombinant IFN. The cultures were then incubated for different periods of time as indicated at $37^{\circ} \mathrm{C}$, in a humidified atmosphere of $5 \% \mathrm{CO}_{2}$ in air. No differences were observed in the number of cells present in control and stimulated cultures at the end of the incubation period.

Detection of $D R^{+}$and $H L A-A, B, C^{+}$monocytes. To determine the percentage of $\mathrm{DR}$ antigen-expressing $\left(\mathrm{DR}^{+}\right)$cells, the culture supernatants were gently removed, and replaced with $50 \mu \mathrm{l} /$ well RPMI 1640 containing $1 \%$ heat-inactivated FCS and $2 \%$ p23,30 anti-DR heteroantiserum (21) or anti-HLA-A,B,C 4D 12 monoclonal antibody (22). Both antibodies were kindly provided by Dr. Dean Mann, National Institutes of Health, Bethesda, MD. The anti-p23,30 antiserum does not cross-react with either HLA-A or with $\beta 2$ microglobulin antigens (21). Cultures were incubated at $4^{\circ} \mathrm{C}$ for $1 \mathrm{~h}$, at which time the culture supernatants were removed and replaced with $50 \mu \mathrm{l} /$ well of RPMI 1640 containing $20 \%$ Low-Tox-H complement (Cedarlane Laboratories, Ltd., Hicksville, NY) and $1 \%$ FCS. The cultures were subsequently incubated for $1 \mathrm{~h}$ at $37^{\circ} \mathrm{C}$. The viability of at least 100 cells per well was determined microscopically 
by trypan blue exclusion. The percentage of $\mathrm{DR}^{+}$or HLA-A,B, $\mathrm{C}^{+}$cells is reported as a mean cytotoxicity index (CI) of triplicate samples, with 95\% confidence limits, based on arcsine square transformation (23). In every anti-DR and complement cytotoxicity assay, the percent of cells lysed in the presence of complement alone was determined. These cells always exhibited a viability $>95 \%$ by 5 to $6 \mathrm{~d}$ of culture. The $\mathrm{CI}$ excludes the nonviable cells from the calculation as follows:

$$
\begin{aligned}
\mathrm{CI} & =100 \times[\% \text { cyt (antibody }+ \text { complement) } \\
& -\% \text { cyt (complement alone) }] /[100 \%-\% \text { cyt (complement alone) }] .
\end{aligned}
$$

The sensitivity of this assay has a $\mathrm{CI}$ of $5 \%$, and its precision is $6.3 \%$. In experiments using the promyelocytic cell line HL60 as target cells for DR antigen induction, the cytotoxicity assay as described directly correlated $\left(r^{2}=0.945\right)$ with FACS analysis by using the same antiserum. ${ }^{2}$ Additionally, this assay has been extensively used in the murine system $(6,9)$ for detection of Ia antigens on macrophages.

Accessory cell capacity of peripheral blood monocytes in the mixed lymphocyte response (MLR). Graded numbers of peripheral blood monocytes were isolated, incubated for $3 \mathrm{~d}$, treated with p23,30 antiDR heteroantiserum and complement to eliminate any remaining $\mathrm{DR}^{+}$ cells, and subsequently cultured for $2 \mathrm{~d}$ with $0.2 \mathrm{ml} /$ well of medium containing maximally active dilutions of either Con A-stimulated culture supernatant (1:5), IFLrA $(30 \mathrm{U} / \mathrm{ml})$, or a corresponding dilution of a control culture supernatant. At this time, the $\% \mathrm{DR}^{+}$cells was determined in a replicate culture. The culture supernatant of the remaining cultures were removed, each well carefully washed once with $100 \mu$ l of RPMI 1640 , and $2-4 \times 10^{5}$ histoincompatible responder lymphocytes in 200 $\mu l$ media were added to each well. The responder cells were isolated from PBMNC after two incubations (one lasting overnight, and the subsequent one for $1 \mathrm{~h}$ ) on plastic flasks to remove adherent cells, followed by nylon-wool column elution to remove residual adherent cells, and finally a treatment with anti-DR (1:100 dilution) and complement ( $1: 10$ dilution). Less than $0.5 \%$ of the resulting cell population stained with nonspecific esterase. Cocultures of peripheral blood monocytes and responder lymphocytes were incubated with or without a 1:20 dilution of p23,30 anti-DR serum at $37^{\circ} \mathrm{C}$ in a humidified atmosphere of $5 \% \mathrm{CO}_{2}$ in air. After $2 \mathrm{~d}$ of incubation, the supernatants of one set of cultures were harvested and tested for IL-2 activity; the remaining set of cocultures were incubated for two additional days, incubated overnight with $0.5 \mu \mathrm{Ci}^{3} \mathrm{H}$-thymidine/well (New England Nuclear, Boston, MA), and harvested, and the radioactivity was determined by liquid scintillation counting.

\section{Results}

Effect of in vitro incubation on peripheral blood monocyte $D R$ antigen expression. Thoroughly washed adherent PBMNC, which were $95-99 \%$ monocytes as determined by nonspecific esterase staining, were incubated for $1-4 \mathrm{~d}$ in medium, and the percentage of $\mathrm{DR}^{+}$cells determined daily (Fig. 1). $70-85 \%$ of freshly obtained peripheral blood monocytes was $\mathrm{DR}^{+}$, as determined by complement-mediated cytotoxicity using anti-DR $($ p23,30) heteroantiserum. In a similar system, using the HL60 promyelocytic cell line, the DR antigen detection by the complement-mediated cytotoxicity assay by using the same antiserum directly correlated with those obtained by FACS analysis, ${ }^{2}$ substantiating the accuracy of the assay used in this study. The DR antigen expression of cultured monocytes declined with time in culture, although the rate and extent of this decline varied from subject to subject. In $83 \%$ of the experiments (15:18), the percentage of $\mathrm{DR}^{+}$cells, as determined by anti-DR and complement-mediated cytotoxicity, progressively declined to $<45 \%$ by days 2-3 and plateaued at that level (Fig. $1 A, C, D$ ). In 3 of 18 experiments, however, the percentage of $\mathrm{DR}^{+}$cells decreased to only $45-65 \%$ range by days 2 through 4 of culture (Fig. $1 B$ ). In parallel experiments, HLA-A, B, C antigen expression, which is present in about $80-95 \%$ of freshly isolated adherent PBMNC, did not decline with time in culture (data not shown). The addition of $1 \mu \mathrm{g} / \mathrm{ml}$ polymyxin $\mathrm{B}$ to these cultures did not significantly alter the rate of loss of DR antigen expression (Fig. 1 D), suggesting that endotoxin contamination of the culture medium was not responsible for the observed loss of monocyte DR antigen expression. Incubation of peripheral blood monocytes in either $10 \%$ human $A B$ serum or serum-free medium did not significantly alter the rate of decline in DR antigen expression, while incubation with zymosan $A$, in agreement with Yem and Parmely (13), resulted in an accelerated loss of DR antigen expression with only $10-17 \%$ of cells expressing DR antigens after $2 \mathrm{~d}$ of incubation. In preliminary experiments, we observed that when we incubated adherent mononuclear cells that were only $60-70 \%$ esterase-positive, the monocyte DR expression declined to a much lesser degree than in cultures of more purified adherent cells containing 95-99\% nonspecific esterase-positive cells. This observation was investigated by adding $10^{5}$ nonadherent autologous PBMNC to the more purified (9599\% nonspecific esterase-positive) adherent PBMNC. As predicted, this resulted in a delay in the rate of decline or in persistence of DR antigen expression by monocytes (Fig. $1 B, C$ ). This suggests that peripheral blood lymphocytes somehow promote the persistence of in vitro monocyte DR expression.

Lymphokine enhancement of monocyte $D R$ antigen expression. Duplicate sets of peripheral blood monocytes $\left(75 \% \mathrm{DR}^{+}\right.$, Fig. 2, left panel) were incubated for $2 \mathrm{~d}$ with medium to reduce their DR antigen expression. One set of these cultures was then incubated with dilutions of either Con A-stimulated PBMNC culture supernatant or a control Con A-supplemented (unstimulated) PBMNC culture supernatant for an additional $2 \mathrm{~d}$, at which time the percentage of $\mathrm{DR}^{+}$monocytes was determined (Fig. 2, center panel). As shown, monocytes incubated for $4 \mathrm{~d}$ in medium or control culture supernatant were $\sim 45 \%$ $\mathrm{DR}^{+}$. Incubation of the monocyte cultures with lymphokines resulted in a dose-dependent increase in the proportion of $\mathrm{DR}^{+}$ monocytes.

To determine whether $\mathrm{DR}^{-}$monocytes can respond to lymphokines, a replicate set of cultures was treated with anti-DR and complement on day 2 in order to lyse any remaining $\mathrm{DR}^{+}$ cells. As shown in Fig. 2., right panel, lymphokines induced elevated percentages of the cultured DR antigen-deficient (DR ${ }^{-}$) monocytes to express DR antigens, indicating that lymphokines are able to induce $\mathrm{DR}$ antigen expression in $\mathrm{a} \mathrm{DR}^{-}$population. Fig. 3 illustrates the kinetics of increased DR antigen expression by adherent PBMNC in response to lymphokines. Monocytes 


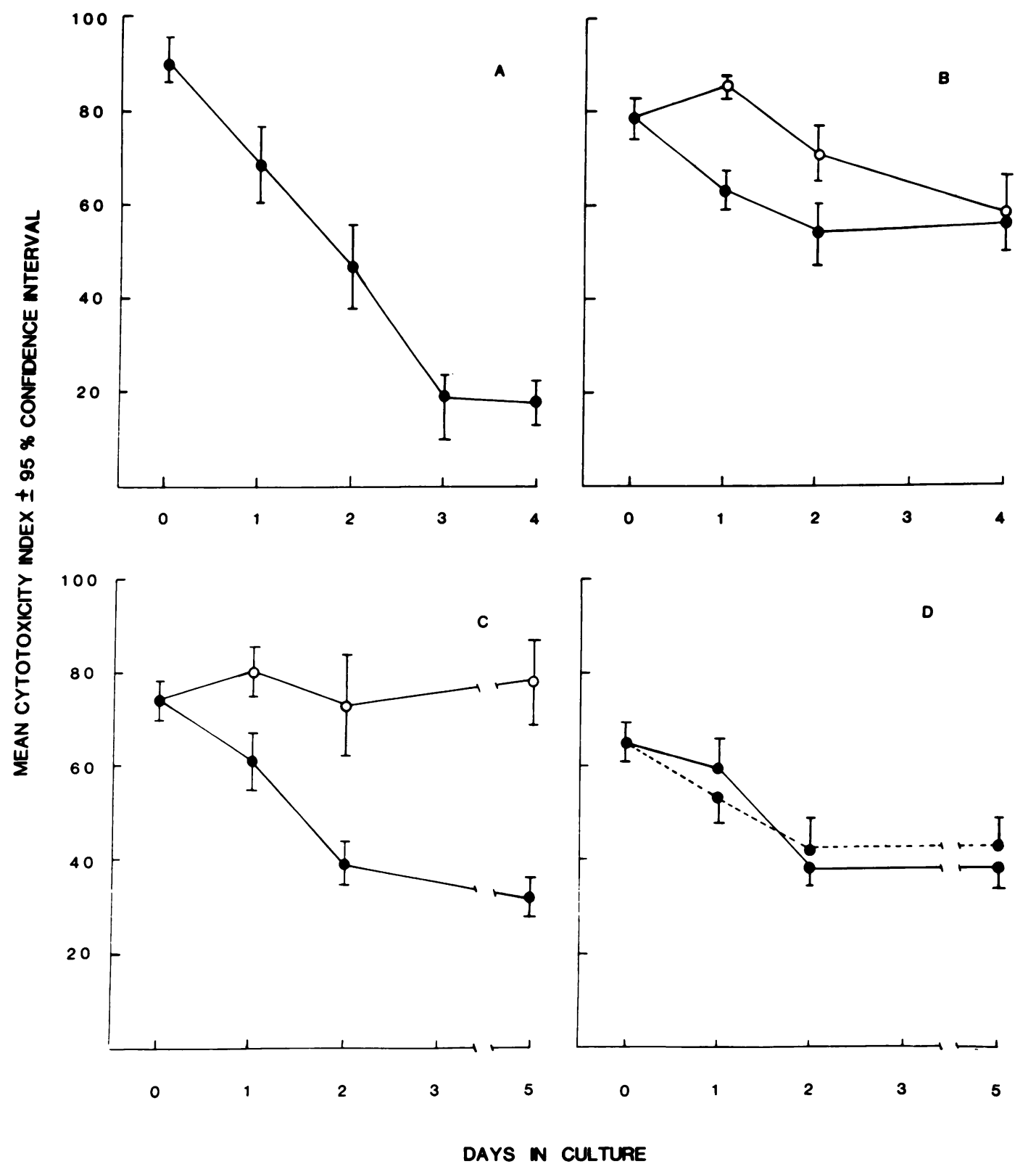

Figure 1. Effects of in vitro incubation on the kinetics of monocyte DR antigen expression. Adherent PBMNC from four subjects were incubated in either culture medium $(-\bullet-)$, culture medium containing $10^{5}$ autologous nonadherent cells $(-\circ-)$, or culture me-

dium containing $1 \mu \mathrm{g} / \mathrm{ml}$ polymyxin B (- $\bullet-)$. The percentage of $\mathrm{DR}^{+}$monocytes was determined daily by antibody and complementmediated cytotoxicity, shown as a $\mathrm{CI} \pm 95 \%$ confidence interval.

were incubated for $3 \mathrm{~d}$ to reduce $\mathrm{DR}$ antigen expression, and then incubated with either lymphokines or a control supernatant. Maximal induction of DR antigen expression was observed by day 2 after incubation with lymphokines. No effect was observed with a control supernatant.

We then investigated whether the mediator(s) in the lymphokine preparation which was responsible for the enhancement

of monocyte DR antigen expression was IFN. Adherent PBMNC were incubated for $2 \mathrm{~d}$ in media to reduce the percentage of $\mathrm{DR}^{+}$monocytes, and then incubated for 2 more days with lymphokine supernatant, which had been preincubated with antiIFN- $\gamma$ antiserum or normal rabbit serum as a control. As can be seen in Fig. 4, rabbit anti-IFN- $\gamma$ antiserum significantly blocked lymphokine enhancement of monocyte DR antigen 


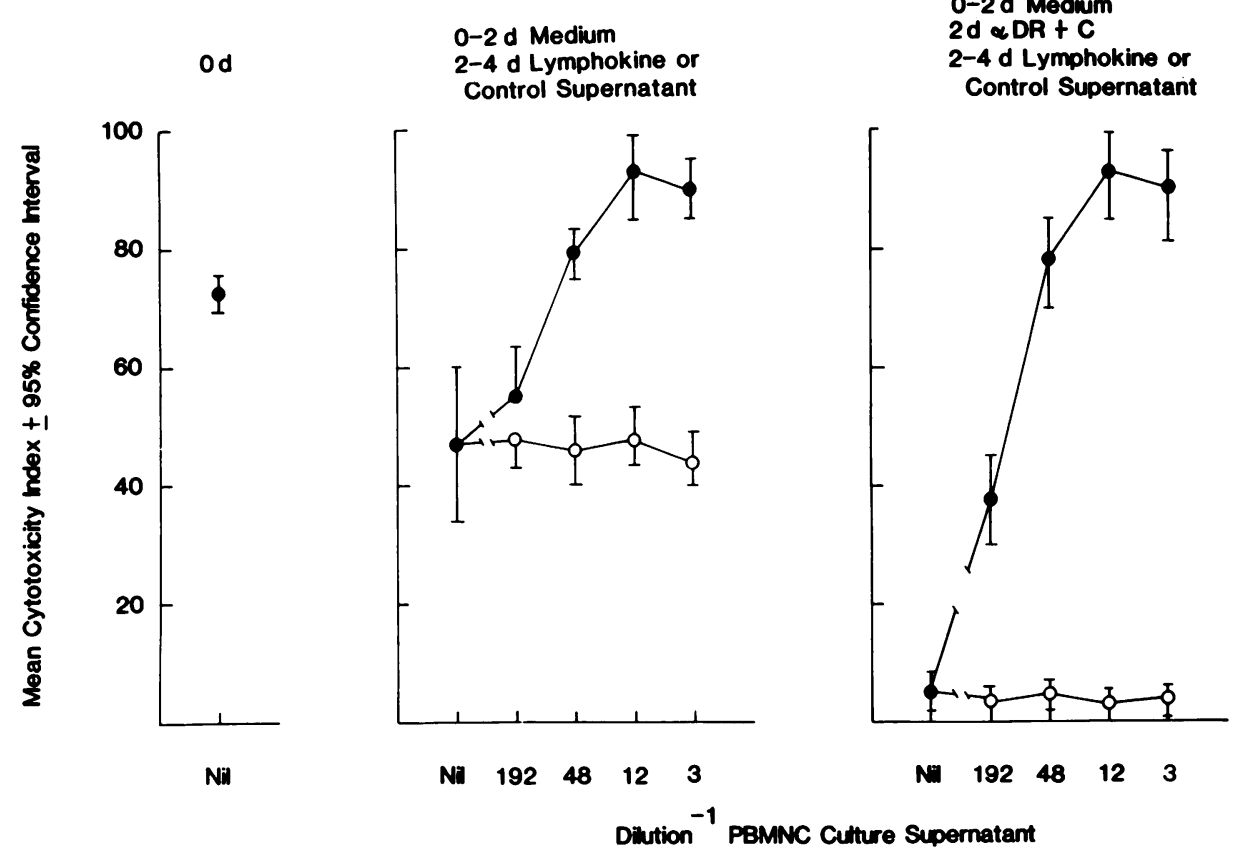

Figure 2. Lymphokine induction of peripheral blood monocyte DR antigen expression. The percentage of $\mathrm{DR}^{+}$monocytes was determined in cultures of freshly obtained adherent PBMNC (left panel); adherent PBMNC incubated for $2 \mathrm{~d}$ in medium and the subsequent $2 \mathrm{~d}$ with either lymphokine-containing $(-\bullet-)$ or control $(-0-)$ culture supernatant (center panel); and adherent PBMNC treated as described for center panel, but additionally treated with anti-DR and complement on day 2 of culture (right panel). Data expressed as in Fig. 1. expression in vitro. To rule out the possibility that the antiIFN- $\gamma$ antiserum has a deleterious effect on monocytes, replicate cultures of monocytes after treatment with lymphokines plus anti-IFN- $\gamma$ antiserum were washed two times and incubated for an additional $2 \mathrm{~d}$ in the presence of lymphokines or control supernatant. Monocytes whose DR expression had been reduced by anti-IFN- $\gamma$ antiserum can subsequently be induced to increase their DR antigen expression by washing off the antibody and the addition of fresh lymphokines (Fig. 4). This supports the view that IFN- $\gamma$ present in the lymphokine supernatant has a

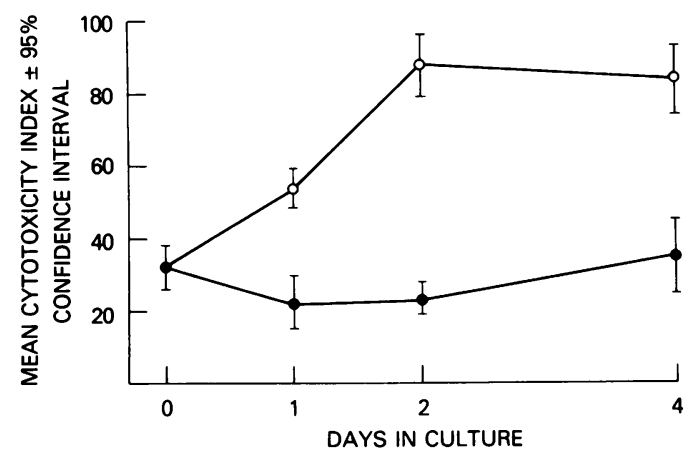

Figure 3. Kinetics in vitro induction of DR antigen expression on peripheral blood monocytes by lymphokines. Adherent PBMNC were incubated for $3 \mathrm{~d}$ in medium alone and the percentage of $\mathrm{DR}^{+}$ monocytes determined (day 0 in this graph). PBMNC were then incubated in the presence of a control supernatant (- - ) or lymphokines (-O-) and monocytes expressing DR antigens measured for the subsequent 1,2 , and $4 \mathrm{~d}$. key role in the induction of DR expression, but does not completely exclude the possibility that other mediators may be involved in this process.

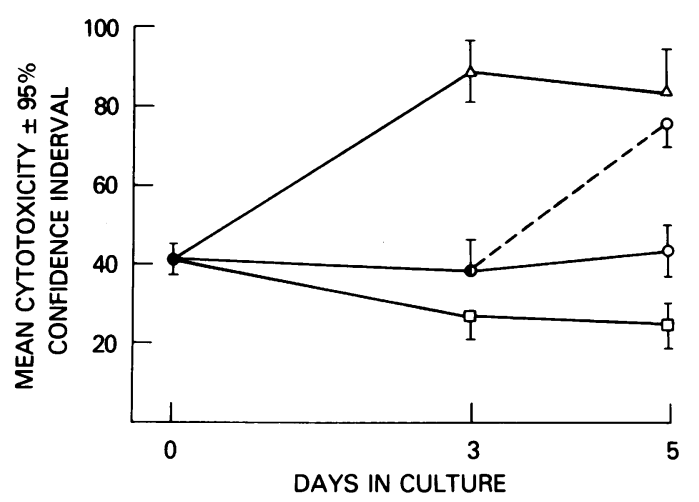

Figure 4. Effect of anti-IFN- $\gamma$ antiserum (anti-synthetic peptide) on lymphokine induction of peripheral blood monocyte DR antigen expression in vitro. Adherent PBMNC (72\% $\left.\mathrm{DR}^{+}\right)$were incubated for $2 \mathrm{~d}$ in medium alone and the percentage of $\mathrm{DR}^{+}$cells calculated (day 0 in this graph). Two sets of cultures were then incubated in the presence of medium alone $(\square-\square)$, or lymphokines preincubated with anti-IFN- $\gamma$ heteroantiserum ( $\bullet-\bullet$ ), or normal rabbit serum $(\Delta-\Delta)$ at 1:10 final dilutions for $90 \mathrm{~min}$ at $4^{\circ} \mathrm{C}$. Three days later the percentage of $\mathrm{DR}^{+}$monocytes was measured in one set of cultures, while replicate cultures of adherent PBMNC which had been incubated with lymphokines plus anti-IFN- $\gamma$ antiserum were washed and reconstituted with control supernatant $(0-0)$ or lymphokine supernatant $(0---0)$. After 2 additional days, the percentage of $\mathrm{DR}^{+}$monocytes in the second set of cultures was determined. Data expressed as in Fig. 1. 
IFN enhancement of peripheral blood monocyte $D R$ antigen expression. The effect of various recombinant IFN on human monocyte DR antigen expression was next determined. Adherent PBMNC were incubated for $2 \mathrm{~d}$ to reduce the DR antigen expression. The cultured cells were also treated with p23,30 anti-DR heteroantiserum and complement in order to remove residual $\mathrm{DR}^{+}$cells, and then incubated with dilutions of either recombinant IFN- $\alpha$ (IFLrA, and IFLrD) or recombinant IFN- $\gamma$ for an additional $2 \mathrm{~d}$; the percentage of $\mathrm{DR}^{+}$monocytes was determined by antibody- and complement-mediated cytotoxicity (Fig. 5). As shown in these representative experiments, adherent PBMNC cultured with IFLrA, IFLrD, or IFN- $\gamma$ contained increased percentages of $\mathrm{DR}^{+}$monocytes. IFN- $\gamma$ was more potent than IFN- $\alpha$, both in inducing higher percentages of $\mathrm{DR}^{+}$monocytes and in that fewer units of antiviral activity were needed to induce a maximal response. These results provide direct evidence that IFN have monocyte DR antigen-inducing activity.

Effect of anti-IFN- $\gamma$ antiserum on monocyte DR antigen expression in vitro. Previous results demonstrate that, in the presence of nonadherent PBMNC, the decline of monocyte DR antigen expression was delayed in vitro and that IFN were able to induce and maintain monocyte DR antigen expression. To determine if the delayed decline in monocyte $D R$ antigen expression in vitro may be due to the presence of IFN- $\gamma$ produced by contaminant $T$ lymphocytes, different dilutions of anti-IFN$\gamma$ antiserum or normal rabbit serum were added to cultured PBMNC (60-70\% nonspecific esterase-positive), and the percentage of monocytes expressing DR antigens was monitored daily. As can be seen in a representative experiment (Fig. 6), increased concentrations of anti-IFN- $\gamma$ antiserum accelerated the rate of decline of monocyte expression of DR in a dosedependent fashion, while normal rabbit serum had no significant effect. In contrast, HLA-A,B,C antigen expression was not affected by these treatments (data not shown). These data, when taken together with the observation that addition of autologous nonadherent cells maintained or delayed loss of DR antigen expression by peripheral blood monocytes, suggest that lymphocyte-derived IFN- $\gamma$ may be playing an important role in the maintenance of the monocyte DR phenotype.
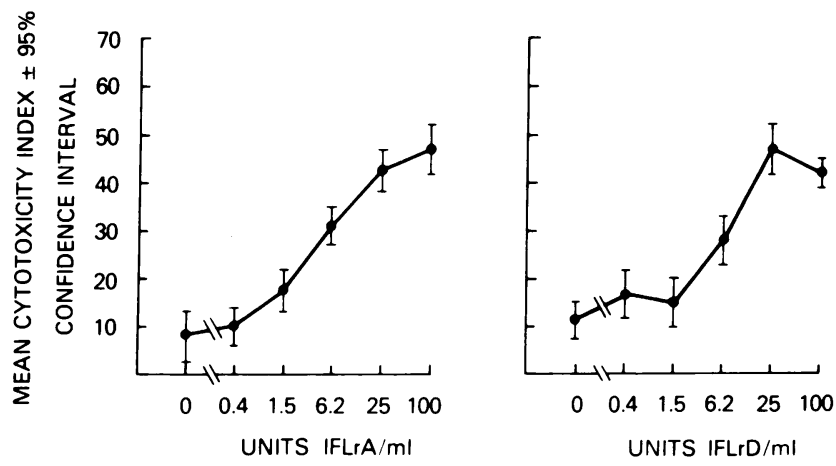

Accessory cell capabilities of lymphokine/IFN-cultured monocytes in the MLR. In order to evaluate the MLR-inducing activity of the IFN-treated monocytes, graded numbers of adherent PBMNC pretreated with p23,30 anti-DR heteroantiserum and complement were preincubated with maximally active dilutions of either lymphokines, IFLrA, or IFLrD, and subsequently were washed and cocultured with histoincompatible purified responder lymphocytes. Lymphocyte activation was evaluated both by proliferation and IL-2 production (Table I). As shown, monocytes incubated with lymphokines or recombinant IFN- $\alpha$ stimulated a significant and dose-dependent IL2 production (up to $23 \mathrm{U} / \mathrm{ml}$ ) and proliferation by allogeneic lymphocytes $(P<0.02$ and $P<0.05$, respectively) as compared with the IL-2 production and proliferation induced by monocytes incubated in medium alone. Both responses were abrogated by adding anti-DR to the cultures, suggesting the DR antigen-dependency of the MLR. The ability of lymphokine/IFN- $\alpha$ incubated monocytes to activate histoincompatible lymphocytes to produce IL-2 was greater than the proliferative response. Control cultured monocytes stimulated $<6 \mathrm{U} / \mathrm{ml}$ of IL-2 production and no proliferation.

\section{Discussion}

Recently, much attention has been focused on the fact that IFN might regulate the expression of histocompatibility antigens in several cell types (24-28). Macrophage expression of the Class II molecules of the major histocompatibility complex has been studied in the mouse (Ia antigens) and in man (DR antigens). It has been reported that murine splenic macrophages become $\mathrm{Ia}^{-}$during in vitro incubation (29). Yem and Parmely (13) have indicated that human peripheral blood monocyte DR antigen expression is stable in culture. In contrast, we report here that human peripheral blood monocytes, cultured in the absence of exogenous signals, express progressively less DR antigen. A possible explanation for this discrepancy is that endogenous lymphokine production by contaminating nonadherent or weakly adherent cells apparently can maintain monocyte DR antigen expression. Indeed, only when the monocytes used in this study were vigorously washed six to eight times before culture did

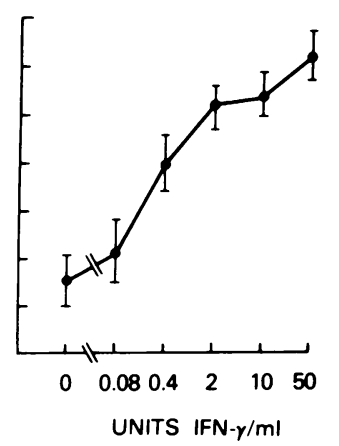

Figure 5. Effect of recombinant leukocyte $(\alpha)$ and gamma $(\gamma)$ IFN on peripheral blood monocyte DR antigen expression. Adherent PBMNC were incubated for $2 \mathrm{~d}$ in medium alone and treated with anti-DR and complement in order to eliminate remaining $\mathrm{DR}^{+}$monocytes. The cultures were washed and the cells incubated for additional $3 \mathrm{~d}$ with dilutions of IFLrA (left panel), IFLrD (center panel), or IFN- $\gamma$ (right panel). The percentage of $\mathrm{DR}^{+}$monocytes on day 5 was determined by antibody and complement-mediated cytotoxicity. 


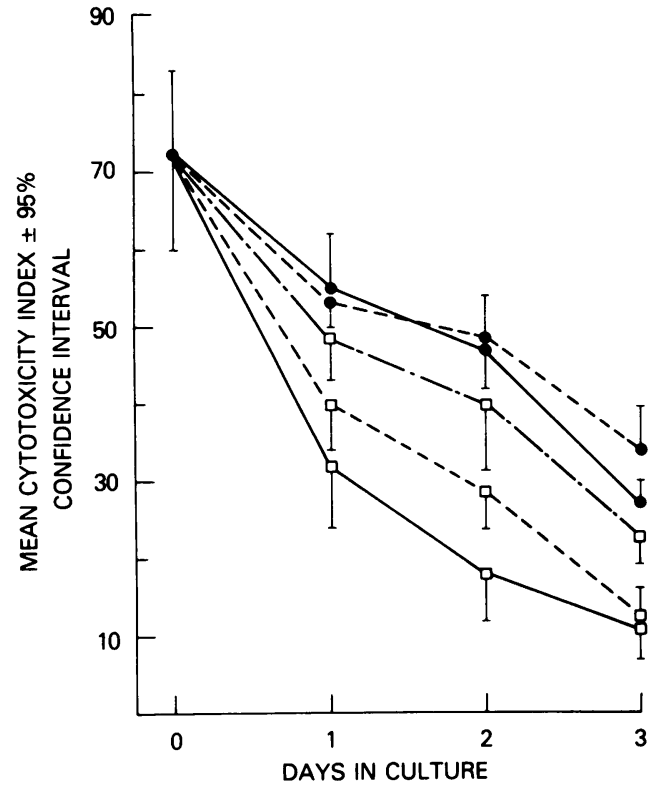

Figure 6. Inhibition of human peripheral blood monocyte DR antigen expression in vitro by anti-human IFN- $\gamma$ antiserum (anti-synthetic peptide). PBMNC (60-70\% nonspecific esterase-positive) were incubated with increasing concentrations of anti-IFN- $\gamma$ antiserum of $1: 10($ (-)), 1:20 (- - --), and 1:40 (-•-ロ-•-), final dilutions, normal rabbit serum at $1: 10$ final dilution $(--\bullet--)$, or medium alone $(-\bullet-)$. The percentage of $\mathrm{DR}^{+}$monocytes were determined daily by $p 23,30$ anti-DR heteroantiserum and complementmediated cytotoxicity. Results are expressed as in Fig. 1.

their DR expression consistently diminish. Furthermore, addition of autologous nonadherent cells to monocyte cultures led to a maintenance of DR antigen expression in vitro, suggesting that contaminating lymphocytes were responsible for the sustained DR expression in vitro in the studies reported by Yem and Parmely (13).

The decrease of human monocyte DR antigen expression in vitro can be accelerated by the addition of a highly specific antiserum directed against a synthetic peptide corresponding to the $\mathrm{N}$-terminus of IFN- $\gamma$ even in the presence of contaminating lymphocytes, suggesting that lymphocyte-derived IFN- $\gamma$ is playing an important role in sustaining DR antigen expression in vitro. This finding also suggests that resting normal peripheral blood lymphocytes must spontaneously secrete low levels of IFN- $\gamma$ in vitro. Perhaps, endogenous production of IFN- $\gamma$ in the individual also accounts for the high percentage of $\mathrm{DR}^{+}$ monocytes found in adult blood.

The fact that an antiserum against human IFN- $\gamma$ significantly blocked lymphokine enhancement of $\mathrm{DR}^{+}$expression by monocytes indicates that IFN- $\gamma$ is at least one of the active mediators in the lymphokine supernatant. This conclusion is strongly supported by the observed direct effect of recombinant human IFN on the induction of DR expression by monocytes, and the evidence that recombinant IFN- $\gamma$ was more potent in inducing DR antigen expression than either of two species of IFN- $\alpha$ in terms of both maximal response elicited, and that fewer units of antiviral activity were needed to induce a maximal response. It should be noted that these experiments do not completely eliminate the possibilities that lymphokines other than IFN may have monocyte DR antigen modulatory activity, or that other lymphokines can synergistically enhance IFN induction of monocyte DR antigen expression. The possibility that contaminating cell types present in peripheral blood monocyte cultures contribute to the enhancement of DR antigen expression is unlikely since in experiments using the homogeneous cloned human promyelocytic cell line HL60, both supernatant lymphokines and recombinant IFN sufficed to enhance DR antigen expression ${ }^{2}$.

The functional concomitant of DR antigen expression in monocytes was studied by assessing their ability to stimulate MLR. Lymphokine/IFN- $\alpha$ preincubated monocytes could stimulate an MLR, as indicated by IL-2 production and histoincompatible lymphocyte proliferation. However, several questions remain unanswered. First, it is unclear why, in the presence of significant IL-2 production, there was only modest, however significant, lymphocyte proliferation. As recently suggested, it is possible that macrophages are less effective than other cell types as alloantigen-presenting accessory cells $(30,31)$. Second, why does IFN- $\alpha$, which is less potent than the unpurified Con A-stimulated PBMNC culture supernatant in inducing DR antigen expression, induce significantly better MLR reactions? Perhaps IFN- $\gamma$ in unpurified Con A-stimulated PBMNC culture supernatants may be counteracted by suppressive lymphokines present in the unpurified culture supernatant.

The observation that IFN can modulate DR antigen expression in human peripheral blood monocytes may have profound clinical implications. Diminished immunocompetence in newborns has been observed in both humans $(32,33)$ and mice $(34$, 35). Neonatal immunodeficient mice also exhibit low Ia antigen expression in spleen macrophages (35). Human cord blood monocytes have also been found to express fewer DR antigens than adult monocytes $(14,36)$. The observations that IFN can increase DR antigens in vitro in both cord and peripheral blood human monocytes suggest that monocyte $\mathrm{DR}$ antigen expression might be diminished and immunoregulation by IFN impaired in patients with immunological deficiencies.

Recent data suggest the existence of alterations in the in vivo regulation of monocyte $\mathrm{DR}$ antigen expression in autoimmune states. Indeed, enhanced percentages of $\mathrm{Ia}^{+}$resident peritoneal macrophages and elevated serum IFN levels have been found in spontaneous ankylosis (ank) mice (F. Hakim, personal communication). In addition, an increased number of $\mathrm{Ia}^{+}$macrophages has been found in the MRL Lpr/Lpr and NZB autoimmune mice $(37,38)$. Treatment of both of the latter strains of mice with prostaglandins, which have been shown to inhibit the IFN- $\gamma$ induction of macrophage Ia antigen expression (10), resulted in both a decline in macrophage Ia antigen expression 
Table I. Allogeneic (DR-dependent) Activation of Human Lymphocytes: Blastogenesis and IL-2 Production*

\begin{tabular}{|c|c|c|c|c|c|c|c|c|c|}
\hline \multirow[b]{3}{*}{$\begin{array}{l}\text { Monocyte } \\
\text { treatment }\end{array}$} & \multirow[b]{3}{*}{$\begin{array}{l}\text { Addition } \\
\text { to } \\
\text { coculture }\end{array}$} & \multicolumn{8}{|c|}{ Number of monocytes/well $\left(\times 10^{4}\right)$} \\
\hline & & \multicolumn{2}{|c|}{10} & \multicolumn{2}{|c|}{5} & \multicolumn{2}{|c|}{2.5} & \multicolumn{2}{|c|}{0} \\
\hline & & $\begin{array}{l}\text { Units } \\
\text { IL-2/ml }\end{array}$ & SI§ & $\begin{array}{l}\text { Units } \\
\text { IL-2/ml }\end{array}$ & SI & $\begin{array}{l}\text { Units } \\
\text { IL-2/ml }\end{array}$ & SI & $\begin{array}{l}\text { Units } \\
\text { IL-2/ml }\end{array}$ & SI \\
\hline \multicolumn{9}{|l|}{ Control } & 1.2 \\
\hline \multicolumn{10}{|l|}{ Lymphokines } \\
\hline containing & - & $17(1.4)^{\| \prime}$ & $2.4 \pi$ & $8.2(1.7)$ & $2.7 \pi$ & $6.8(0.1)$ & 1.3 & $5.7(0.6)$ & 0.9 \\
\hline supernatant & anti-DR & $6.6(0.1)$ & 1.2 & $5.9(0.3)$ & 0.9 & $6.9(0.4)$ & 1.2 & $7.5(0.8)$ & 0.7 \\
\hline \multirow[t]{2}{*}{ IFLrA } & - & $21.4(1.3)^{\| \prime}$ & $2.7 \pi$ & $12.5(0.8) \pi$ & $2.5 \pi$ & $7(1.3)$ & $1.6 \pi$ & $6.6(0.2)$ & 1.3 \\
\hline & anti-DR & $9.2(3.2)$ & 1.1 & $7.4(1.1)$ & 0.9 & $8.8(0.2)$ & 1.1 & $7.4(0.4)$ & 1.3 \\
\hline \multirow[t]{2}{*}{ IFLrD } & - & $23.3(2.5)^{\|}$ & $2.7 \pi$ & $17.2(1.3)^{\prime \prime}$ & $1.8 \pi$ & $9.1(3)$ & 1.3 & $7.3(0.6)$ & 0.9 \\
\hline & anti-DR & $5.1(0.2)$ & 1.3 & $6.3(0.5)$ & 1.4 & $6(0.1)$ & 1.2 & $7.2(0.4)$ & 1.1 \\
\hline
\end{tabular}

* Graded numbers of adherent PBMNC were incubated for $3 \mathrm{~d}$ in medium to decrease DR antigen expresion, treated with anti-DR heteroantiserum plus complement in order to eliminate remaining $\mathrm{DR}^{+}$monocytes, and incubated for 2 additional days in the presence of medium alone, control supernatant, lymphokine-containing supernatant, IFLrA, or IFLrD. The percentage of $\mathrm{DR}^{+}$monocytes at this time, as measured by anti-DR plus complement cytotoxicity assay, showed increased DR antigen expression of monocytes incubated with lymphokine (68\%), IFLrA $(42 \%)$, and IFLrD (49\%) as compared with control $(7 \%)$ or medium alone $(8 \%)$. Then, the remaining cultures were washed and $3.5 \times 10^{5}$ plastic nonadherent, nylon wool nonadherent, $D^{-}$PBMNC were added to each well. In addition, p23,30 anti-DR heteroantiserum at a 1:20 final dilution, was also added to some cocultures as indicated. One set of cocultures was incubated for $2 \mathrm{~d}$, at which time the IL-2 activity of the culture supernatant was determined, while a replicate set was incubated for $4 \mathrm{~d}$, incubated overnight with $0.5 \mathrm{mCi}\left[{ }^{3} \mathrm{H}\right]$ thymidine, and the incorporated radioactivity counted by a liquid scintillation counter. ¥ Mean units per milliliter IL-2 of duplicate cultures. Standard deviation is indicated in parenthesis after each mean. §Stimulation index (SI) was calculated as: Mean cpm in cocultures containing treated monocytes/ mean cpm in cocultures containing monocytes incubated in medium alone. "Significantly different from effector cells incubated in the presence of control macrophages, $P<0.02$ by $t$ test. T Significantly different from effector cells incubated in the presence of control macrophages, $P<0.05$ by $t$ test.

and failure to develop signs of the autoimmune state $(38,39)$. Conversely, normal mice which were neonatally thymectomized and injected with the IFN inducer polyriboimosimic: polyribocytidylic acid with and without lipopolysaccharide have been shown to develop an autoimmune state (40).

In humans, high serum IFN titers, as well as unusual IFN species, have been described in active systemic lupus erythematosus (SLE) patients (41). Furthermore, the presence in the sera of SLE patients of antibodies that block the binding of antiIa antibodies to Ia-positive targets has also been described (42). Preliminary observations in our laboratory indicate that peripheral blood monocytes from patients with SLE express fewer DR antigens than normal monocytes (43). Presumably, the capacity to induce immunological reactions varies with $D R$ expression, but the physiological role and contribution of this phenomenon to disease states remain to be established.

\section{Acknowledgments}

We thank Dr. S. Pestka and Dr. P. Gray of Hoffmann LaRoche and Dr. D. Goeddel of Genentech, Inc. for their invaluable gifts of interferons, and Dr. D. Mann for the gift of anti-DR and anti-HLA-A, B, C antibodies. We also thank Drs. D. Plutznik, D. Mann, M. L. Satz, and F. Hakim for critical review of the manuscript.

Dr. Johnson is supported by National Institutes of Health grant CA27590.

\section{References}

1. Bergholtz, B. O., and E. Thorsby. 1978. HLA-D restriction of the macrophage-dependent response of immune human $T$ lymphocytes to PPD in vitro: inhibition by anti-HLA DR antisera. Scand. J. Immunol. 3:63-73.

2. Muchmore, A. V., J. M. Decker, and D. L. Mann. 1982. Evidence that antisera that react with products of the human HLA-DR locus may block in vitro antigen-induced proliferation by inducing suppression. $J$. Immunol. 128:2063-2066.

3. Allison, J. P., L. E. Walker, W. A. Russell, M. A. Pellegrine, S. Ferrone, R. A. Reisfield, J. A. Frelinger, and J. Silver. 1978. Murine Ia and human DR antigens: homology of amino-terminal sequences. Proc. Natl. Acad. Sci. USA. 75:3953-3956.

4. Lunney, J. K., D. L. Mann, and D. H. Sachs. 1979. Sharing of Ia antigens between species: Ia specificities shared between mice and human beings. Scand. J. Immunol. 10:403-413. 
5. Steinman, R. M., W. Nogueira, M. D. Witmer, J. D. Tydings, and I. S. Mellman. 1980. Lymphokine enhances the expression and synthesis of Ia antigens in cultured mouse peritoneal macrophages. $J$. Exp. Med. 152:1248-1261.

6. Steeg, P. S., R. N. Moore, and J. J. Oppenheim. 1980. Regulation of murine macrophages Ia-antigen expression by products of activated spleen cells. J. Exp. Med. 152:1734-1744.

7. Walker, E. B., L. L. Lanrer, and N. L. Warner. 1982. Concomitant induction of the cell surface expression of Ia determinants and accessory cell function by a murine macrophage tumor cell line. J. Exp. Med 155:629-634.

8. Birmingham, J. R., R. W. Chesnut, J. W. Kappler, P. Marrack, R. Kubo, and H. M. Gray. 1982. Antigen presentation to T cell hybridomas by a macrophage cell-line: an inducible function. J. Immunol. 128:1491-1492.

9. Steeg, P. S., R. N. Moore, H. M. Johnson, and J. J. Oppenheim. 1982. Regulation of murine macrophage Ia antigen expression by a lymphokine with immune interferon activity. J. Exp. Med., 156:17801793.

10. Steeg, P. S., H. M. Johnson, and J. J. Oppenheim. 1982. Regulation of murine macrophage Ia antigen expression by an immune interferon-like lymphokine: inhibitory effect of endotoxin. J. Immunol. 129:2402-2406.

11. Snyder, D. S., and E. R. Unanue. 1982. Corticosteroids inhibit murine macrophage Ia expression and interleukin I production. J. Immunol. 129:1803-1805.

12. Snyder, D. S., D. I. Beller, and E. R. Unanue. 1982. Prostaglandins modulate macrophage Ia expression. Nature (Lond.). 299:163-165.

13. Yem, A. W., and M. S. Parmely. 1981. Modulation of Ia-like antigen expression and antigen-presenting activity of human monocytes by endotoxin and zymosan A. J. Immunol. 127:2245-2251.

14. Sztein, M. B., P. S. Steeg, R. Stiehm, D. Mann, M. Blaese, and J. J. Oppenheim. 1983. Modulation of human cord blood monocyte DR antigen expression in vitro by lymphokines and interferon. In Interleukins, Lymphokines and Cytokines. J. J. Oppenheim and S. Cohen, editors. Academic Press, Inc., New York. 299-305.

15. Dayton, E. T., B. Perussia, and G. Trinchieri. 1983. Correlation between differentiation, expression of monocytic-specific antigens, and cytotoxic functions in human promyelocytic cell lines treated with leukocyte condition medium. J. Immunol. 130:1120-1128.

16. Farrar, J. J., S. B. Mizel, J. Fuller-Farrar, W. L. Farrar, and M. L. Hilfiker. 1980. Macrophage-independent activation of helper T cells. I. Production of interleukin 2. J. Immunol. 125:793-798.

17. Staehelin, T., D. S. Hobbs, H. Kung, C.-Y. Lai, and S. Pestka. 1981. Purification and characterization of recombinant human leukocyte interferon (IFLrA) with monoclonal antibodies. J. Biol. Chem. 256:97509754.

18. Gray, P. W., D. W. Leung, D. Pennica, E. Yelverton, R. Najurian, C. C. Simonsen, R. Derynck, P. J. Sherwood, D. M. Wallace, S. L. Berger, A. D. Levinson, and D. V. Goeddel. 1982. Expression of human immune interferon cDNA in E. coli and monkey cells. Nature (Lond.). 295:503-508.

19. Johnson, H. M., M. P. Langford, B. Lakhchaura, T.-S. Chan, and G. J. Stanton. 1982. Neutralization of native human gamma interferon (HuIFN $\gamma$ ) by antibodies to a synthetic peptide encoded by the $5^{\prime}$ end of the HulFN $\gamma$ cDNA. J. Immunol. 129:2357-2359.

20. Tucker, S. B., R. V. Pierre, and R. E. Jordon. 1977. Rapid identification of monocytes in a mixed mononuclear cell preparation. J. Immunol. Methods. 14:267-269.
21. Humphries, R. E., J. M. McCune, L. Chess, H. C. Herrmann, D. J. Malenka, D. L. Mann, P. Parham, S. F. Schlossman, and J. L. Strominger. 1976. Isolation and immunologic characterization of a human B lymphocyte specific cell surface antigen. J. Exp. Med. 144:98112.

22. Haynes, B. F., E. G. Reisner, M. E. Hemter, J. L. Strominger, and G. S. Eisenbarth. 1982. Description of a monoclonal antibody defining an HLA allotypic determinant that include specificities within the B-5 cross-reacting group. Hum. Immunol. 4:273-285.

23. Sokal, R. R., and F. S. Rohlf. 1969. Biometry. W. H. Freeman \& Co., San Francisco. 386-387.

24. Vignaux, S., and I. Gresser. 1978. Enhanced expression of histocompatibility antigens on interferon-treated mouse embryonic fibroblasts. Proc. Soc. Exp. Biol. Med. 157:456-460.

25. Burrone, O. R., and C. Milstein. 1982. Control of HLA-A, B, $\mathrm{C}$ synthesis and expression in interferon-treated cells. $E M B O$ (Eur. Mol Biol. Organ.) J. 1:345-349.

26. Basham, T. Y., M. F. Bourgeade, A. A. Creasey, and T. C. Merigan. 1982. Interferon increased HLA synthesis in melanoma cells: interferon-resistant and interferon-sensitive cell lines. Proc. Natl. Acad. Sci. USA. 79:3265-3269.

27. Wallach, D., M. Fellous, and M. Revel. 1982. Preferential effect of $\gamma$ interferon on the synthesis of HLA antigens and their mRNAs in human cells. Nature (Lond.). 299:833-836.

28. Wong, G. H. W., I. Clark-Lewis, J. L. McKimm-Breschkin, and J. W. Schrader. 1982. Interferon- $\gamma$-like molecule induces Ia antigens on cultured mast cell progenitors. Proc. Natl. Acad. Sci. USA. 79:69896993.

29. Cowing, C., B. D. Schwartz, and H. B. Dickler. 1978. Macrophage Ia antigens. I. Macrophage populations differ in their expression of Ia antigens. J. Immunol. 120:378-384.

30. Kuntz Crow, M., and H. G. Kunkel. 1982. Human dendritic cells: major stimulators of the autologous and allogeneic mixed leucocyte reactions. Clin. Exp. Immunol. 49:338-346.

31. Van Voorhis, W. C., L. S. Hair, R. M. Steinman, and G. Kaplan. 1982. Human dendritic cells. Enrichment and characterization from peripheral blood. J. Exp. Med. 155:1172-1187.

32. Blaese, R. M., and E. C. Lawrence. 1977. Development of macrophage function and the expression of immunocompetence. In Development of Host Defenses. M. D. Cooper and D. H. Dayton, editors. Raven Press, New York. 201-207.

33. Lubens, R. G., S. E. Gard, M. Soderberg-Warner, and E. R. Stiehm. 1982. Lectin dependent and natural killer cytotoxic deficiencies in human newborns. Cell. Immunol. 74:40-53.

34. Yu, C. Y., E. G. Calamai, and E. R. Unanue. 1979. A defect in the antigen presenting function of macrophages from neonatal mice. Nature (Lond.). 282:327-329.

35. Snyder, D. S., C. Y. Lu, and E. R. Unanue. 1982. Control of macrophage Ia expression in neonatal mice: role of a splenic suppressor cell. J. Immunol. 128:1458-1465.

36. Tweady, D. J., J. E. Baley, B. Z. Schacter, and J. J. Ellner. 1982. Decreased surface expression of HLA-DR antigen expression on human neonatal cord blood monocytes. Clin. Res. 30:359A. (Abstr.)

37. Lu, C. Y., and E. R. Unanue. 1982. Spontaneous T-cell lymphokine production and enhanced macrophage Ia expression and tumoricidal activity in MRL-Lpr mice. Clin. Immunol. Immunopathol. 25:213-222. 
38. Kelley, V. E., and J. B. Roths. 1982. Increase in macrophage Ia expression in autoimmune mice: role of the Lpr gene. J. Immunol. 129:923-925.

39. Zurier, R. B. 1982. Prostaglandins, immune responses, and murine lupus. Arthritis Rheum. 25:804-809.

40. Smith, H. R., D. Green, E. Raveche, P. Smathers, R. Gershon, and A. D. Steinberg. 1982. The induction of autoimmunity in normal mice. Fed. Proc. 41:954 (Abstr.)

41. Preble, O. T., R. J. Black, R. M. Friedman, J. H. Klippel, and J. Vilcek. 1982. Systemic lupus erythematosus: presence in human serum of an unusual acid labile leukocyte interferon. Science (Wash. DC). 216:429-431.

42. Okudaira, K., R. P. Searles, J. S. Goodwin, and R. C. Williams, Jr. 1982. Antibodies in the sera of patients with systemic lupus erythematosus that block the binding of monoclonal anti-la to Ia-positive targets also inhibit the autologous mixed lymphocyte response. J. Immunol. 129:582-586.

43. Nagai, H., M. B. Sztein, P. S. Steeg, J. J. Hooks, A. D. Steinberg, and J. J. Oppenheim. 1983. Decreased DR expression by peripheral blood monocytes from patients with systemic lupus erythematosus. Clin. Res. 31:453A. (Abstr.) 